\title{
Cholinergic stimulation of the brain and avoidance behavior'
}

Cannulas were implanted in the lateral hypothalamus (LH) in seven rats and in the septal area in two additional rats. The placement of a few micrograms of carbachol in the septal area produced a marked impairment in the performance of a modified Sidman avoidance response. When placed in the LH, however, carbachol elicited a very marked increase in the number of avoidance responses.

Behavioral effects frequently occur following the direct placement of cholinergic agents, such as acetylcholine and carbachol, in specific brain loci of animals (Miller, 1965). One major effect is the elicitation of drinking in rats following cholinergic stimulation in any one of 11 different diencephalic and limbic system loci, including the septal area, the amygdala, and the LH (Fisher \& Coury, 1962; Grossman, 1964a; Stein \& Seifter, 1962). It is significant that all of the sites associated with this effect are either in, or are closely connected with, Papez's (1937) anatomical circuit. Thus, this represents one example of an entire neural system in which cholinergic stimulation produces behavioral consequences.

This particular neural system has long been of interest with regard to learned behavior. Structures in it may mediate affective and emotional processes (Brady, 1958), and thereby influence the acquisition or the performance of learned responses. In addition, an important role in the reinforcement process has been ascribed to at least one structure in this system, the LH (Olds, 1962). The possibility that cholinergic activity may be associated with these functions has been suggested by two recent studies. Grossman (1964b) has shown that cholinergic stimulation of the septal area impairs the acquisition and performance of two types of discrete-trial avoidance responses. Olds et al (1964) have shown that there may be a cholinergic component involved in the well-known lateral hypothalamic self-stimulation phenomenon, since their rats learned to press a lever in order to self-inject minute amounts of cholinergic agents into the LH. Thus, it appears that cholinergic stimulation in these structures can affect learned behavior.

The present study reports the effects of cholinergic stimulation in the septal area and the LH on the performance of an active avoidance response.

Method

The Ss were nine naive male rats weighing $300-350$ $\mathrm{gm}$ at the time of operation. Guide cannulas, made of 22 gauge needle tubing, were chronically implanted in the LH in seven rats (with the skull held level, the stereotaxic coordinates were A 5.5-6.0, L 2.0, and
7.5-8.0 $\mathrm{mm}$ down from the cortex) and in the septal area in two rats (at A 11.4-12.5, L 0.5, and $4.5 \mathrm{~mm}$ below the cortex). Inner cannulas, made of 28 gauge tubing, served as the chemical inserters.

The rats were trained postoperatively in a Sidman avoidance task, as modified by Teitelbaum \& Derks (1958). The manipulandum was a hollow, cylindrical plastic wheel, 2 in. in diameter, $1.5 \mathrm{in}$. wide, with 10 1/8-in. spokes spaced evenly around the circumference. Two cams were attached to the wheel in such a way as to ensure that it would take a maxdmum of a half-revolution to turn off shocks. A successful "response" thus consisted of a half-revolution or less, depending on the initial position of the wheel. The shocks, which were delivered by a grid scrambler, were $0.4 \mathrm{ma}$ in intensity and $90 \mathrm{msec}$. in duration, and they were repeated once a second (S-S interval of 0.9 sec.).

When a $S$ was receiving shock, a single response postponed the next shock for 1 sec. Each successive response resulted in the same short postponement, unless there were four or more responses within 1 sec. of each other. When that occurred, shock was postponed for 20 sec., and each successive response during this long postponement started the delay period over again. If the rat made no responses within $20 \mathrm{sec}$., the long delay period ended, shock came on again, and the rat once more had two shock postponement periods available. Thus, there were two $R-S$ intervals in this schedule.

After one or two training sessions, formal testing was begun. On every testing day, 15-20 $\mathrm{min}$. of baseline data were collected. Then, one of the following was performed: (a) the placement of 5-15 $\mu \mathrm{g}$ of a crystalline chemical substance or $0.5-2.0 \mu 1$ of a substance in solution into the cannulas (chemical stimulation); or, (b) nothing was placed into the cannulas (sham stimulation). The rat was then returned to the experimental cage and his performance was observed for a period of time. The chemical stimulation techniques were similar to those used by Stein \& Selfter (1962) and Routtenberg (1965). The amounts of chemical used here were estimated on the basis of the measurements reported by these investigators. Chemical stimulation was alternated with one or two days where no such stimulation was given.

\section{Results}

After rapidly acquiring the wheel-turning response, the Ss first maintained a high rate of responding with infrequent pauses. By the end of one or two training sessions, however, they had already shifted to the typical pattern seen with the present schedule and shock parameters (Teitelbaum \& Derks, 1958). This pattern 
consisted of a rate of 25-35 responses per minute, some of which were spaced in such a way as to keep $S$ within the long shock postponement period. For the most part, however, the predominant aspect of the pattern was this sequence: a burst of 4-8 responses; a 20-sec. pause; the taking of one or two shocks; and a new burst of 4-8 responses. Thus, avoidance was by no means perfect. The onset of shock, however, nearly always elicited a rapid burst of four or more responses.

The major finding of this study was that injections of a few micrograms of carbachol produced opposite effects when placed in the septal area and the LH. In the septal area, the carbachol always produced a pronounced decrease in responding. The Ss often made few responses or no responses at all for intervals of 2-5 min., during which time they hopped about and squealed. In the $\mathrm{LH}$, however, carbachol increased the response rate more than three-fold with the number of shocks taken being halved (Table 1). The latency of onset of the septal effect was 5-10 $\mathrm{min}$; that of the LH effect was 2-4 min. In both brain areas, these effects lasted for about two hours.

Excluded from Table 1 are the data for one of the seven LH Ss. Unlike the other six Ss, this rat's cannulas had been implanted at $\mathrm{L} 2.6$ instead of $\mathrm{L} 2.0$, and carbachol produced no significant changes in his performance. Also excluded from Table 1 are data from those days when carbachol elicited convulsions. This occurred about $20 \%$ and $5 \%$ of the time for the septal area and $\mathrm{LH} \mathrm{Ss,} \mathrm{respectively.} \mathrm{The} \mathrm{convulsions} \mathrm{were}$ produced by amounts of carbachol estimated to be greater than $15 \mu \mathrm{g}$.

Some preliminary results were obtained with control chemicals. In the LH, potassium chloride was not observed to have any significant effects on avoidance performance; procaine $\mathrm{HCl}$, in either crystalline form or in solution, produced an impairment. The placement of atropine sulfate in either the LH or the septal area had no direct effects on performance. However, pretreatment with atropine, either in the appropriate brain site or via an I.P. injection, increased the latency of onset of the carbachol effects.

Histological verification showed that the septal area

Table 1.

\begin{tabular}{lccccc} 
Animal & $N^{1}$ & $\begin{array}{c}\text { Mean Responses/min. } \\
\text { Baseline }\end{array}$ Corbachol & \multicolumn{2}{c}{$\begin{array}{c}\text { Mean Shocks } / \text { min. } \\
\text { Baseline }\end{array}$ Carbachol } \\
\hline Septal area: & & & & \\
S-lu2 & 4 & $41.8 \pm 6.2^{3}$ & $19.5 \pm 4.6$ & $6.6 \pm 3.1$ & $16.6 \pm 7.3$ \\
S-2b & 3 & $28.6 \pm 5.2$ & $15.4 \pm 2.4$ & $7.1 \pm 3.5$ & $19.9 \pm 3.5$ \\
Mean & $35.2 \pm 6.6$ & $17.5 \pm 2.1$ & $6.9 \pm 0.0$ & $18.3 \pm 1.7$ \\
Lateral Hypothalamus: & & & \\
LH-lu & 3 & $30.7 \pm 2.7$ & $134.3 \pm 12.3$ & $4.0 \pm 0.8$ & $1.0 \pm 0.7$ \\
LH-2b & 4 & $31.9 \pm 9.1$ & $110.6 \pm 9.0$ & $2.1 \pm 1.1$ & $1.9 \pm 1.3$ \\
LH-3b & 3 & $31.5 \pm 3.8$ & $83.8 \pm 13.3$ & $3.7 \pm 1.8$ & $1.2 \pm 0.4$ \\
LH-4u & 3 & $20.8 \pm 0.6$ & $77.4 \pm 11.7$ & $4.2 \pm 1.9$ & $2.4 \pm 0.6$ \\
LH-6b & 4 & $32.3 \pm 14.4$ & $83.3 \pm 11.5$ & $2.6 \pm 0.7$ & $1.4 \pm 0.0$ \\
LH-7b & 3 & $35.7 \pm 4.1$ & $110.3 \pm 24.8$ & $1.5 \pm 0.6$ & $1.0 \pm 0.7$ \\
Mean & $30.5 \pm 4.6$ & $100.0 \pm 20.3$ & $3.0 \pm 1.0$ & $1.5 \pm 0.5$ \\
\hline
\end{tabular}

1. Number of sessions 2. u=unilateral stimulation; $b=$ bilateralstimulation 3. Mean plus or minus one S. D. implantations were in the rostral lateral septal nuclei, while all of the LH placements were in the lateral hypothalamic, medial forebrain bundle area at the level of the ventromedial nuclei.

\section{Discussion}

The impairment of avoidance behavior seen here after the placement of carbachol in the septal area is in agreement with Grossman's (1964b) results. Since different avoidance tasks were used in these two experiments-Grossman used a shuttle box task as well as a discrete-trial lever-press task, whereas the present study used a Sidman task-this impairment seems to be quite a general one with regard to active avoidance behavior.

The enhancement seen after insertion of carbachol into the LH has not been reported previously. That this effect was not due to any type of a lesion is indicated by the result that procaine in the LH caused impairment. Also supporting this idea is the similarity of the LH and septal area effects to the data from electrical stimulation studies (Olds \& Olds, 1962; Routtenberg \& Olds, 1963; Stein, 1965). Thus, the present results provide further evidence for the avoidance-reducing properties of septal stimulation and the avoidance-enhancing nature of LH stimulation. In addition, the results indicate that there may be cholinergic components involved in these functions.

\section{References}

Brady, J. V. The paleocortex and behavioral motivation. In H. F, Harlow and C. N. Woolsey (Eds.), Biological and biochemical bases of behavior. Madison: University Wisconsin Press, 1958.

Fisher, A. E., \& Coury, J. N. Cholinergic tracing of a central neural circuit underlying the thirst drive. Science, 1962, 138, 691-693.

Grossman, S. P. Behavioral effects of chemical stimulation of the ventral amygdala. $J$. comp. physiol. Psychol., 1964a, 57, 29-36.

Grossman, S. P. Effect of chemical stimulation of the septal area on motivation. J. comp. physiol. Psychol., 1964b, 58, 194-200.

Miller, N. E. Chemical coding of behavior in the brain. Science, $1965,148,328-338$.

Olds, M. E., \& Olds, J. Approach-escape interactions in the rat brain. Amer. J. Physiol., 1962, 203, 803-810.

Olds, J. Hypothalamic substrates of reward. Physiol. Rer., 1962, 42, 554-604.

Olds, J., Yuwiler, A., Olds, M. E., \& Yun, C. Neurohumors in hypothalamic substrates of reward. Amer. J. Physiol., 1964, 207, 242-254.

Papez, J. W. A proposed mechanism of emotion. Arch. Neurol. Psychiat., Chicapo, 1937, 38, 725-743.

Routtenberg, A. The effects of chemical stimulation in dorsal midbrain tegmentum on self-stimulation in hypothalamus and septal area. Psychon. Sci., 1965, 3, $41-42$.

Routtenberg. A., \& Olds, J. The attenuation of response to an aversive brain stimulus by concurent rewarding septal stimulation. Fed. Proc, 1963, 22, 515. (Abstract)

Stein. L. Facilitation of avoidance behavior by positive brain stimulation. J. comp. physiol. Psychol., 1965, 60, 9-19.

Stein. L., \& Seifter, J. Muscarinic synapses in the hypothalamus. Amer. J. Physiol., 1962, 202, 751-756.

Teitelbaum, P.. \& Derks, P. The effect of amphetamine on forced drinking in the rat. J. comp. physiol. Psychol., 1958, 51, 801-810.

\section{Note}

1. I thank Dr. Philip Teitelbaum for his valuable suggestions This research was supported by National Science Foundation Grant GB-3480 and PHS Grant NB-05937 to Dr. Teitelbaum. 